\title{
Use of Transportation Methodology to Maximize Profits of a Private Transporter
}

\author{
Oziely Armenta ${ }^{1}$, Aide Maldonado-Macías ${ }^{1}$, Liliana Avelar Sosa ${ }^{1}$, Guillermo Cortés \\ Robles $^{2}$, Jorge Limón ${ }^{3}$ \\ ${ }^{1}$ Universidad Autónoma de Ciudad Juarez, \\ Department of Industrial Engineering, Ciudad Juarez, \\ Mexico \\ ${ }^{2}$ Instituto Tecnológico de Orizaba, \\ Division of Research and Postgraduate Studies, Orizaba, \\ Mexico \\ ${ }^{3}$ Universidad Autónoma de Baja California, \\ Faculty of Engineering, Architecture and Design, Mexicali, \\ Mexico \\ danyelita_3@hotmail.com,\{amaldona,liliana.avelar\}@uacj.mx, gcrobles@itorizaba.edu.mx, \\ jorge.limon@uabc.edu.mx
}

\begin{abstract}
This study addresses the transport of fresh fruit and vegetables from an independent transporter in Ciudad Juarez, México. Even though the main issue relies on the transport itself, an alternate objective function was proposed to maximize profits of the transporter by considering certain constraints. The main objective of this research is to determine the optimal amount of fruit and vegetables that should be purchased to be transported later to the different destinations to generate the maximum profitability that is possible. The problem is tackled by means of classical methods of problem solving. Moreover, the simplex method employed enables to identify the constraints and determine the optimal solution to the problem that satisfies transport requirements and generates the highest profitability. Finally, results demonstrate that the maximum profit that can be gained is $\$ 1,840.00$ Mexican pesos during a single trip, satisfying demand of three different businesses.
\end{abstract}

Keywords: Optimal solution, transport, simplex method.

\section{Introduction}

This study describes the problem faced by a private transporter in the transport of fresh fruit and vegetables in Ciudad Juarez, Mexico. An alternate objective function was proposed to maximize profits of the transporter by considering restrictions of product capacity, costs, and sale prices.

The independent transporter has experienced monetary losses, since he does not rely on a plan determining the amount of product transported that is profitable to his business. Therefore, the main goal of this study is to find the optimal configuration of 
products that must be purchased to be later transported, and which could generate the maximum profitability. In order to achieve this, the research relies on the simplex and transportation methods. Demand is considered weekly, for every two weeks, and monthly.

\section{Literature Review}

Literature has addressed several methods to solve maximization and transport problems. However, this research views them as two separate elements, since the transportation method is usually used for minimization. Therefore, both this one and the simplex method are here combined to maximize resources. Similarly, since they have been largely considered as classical methods for the solution of this type of problems, the two remain applicable to and efficient for real and contemporary situations.

This second section of the paper is divided in several subsections that introduce basic concepts from the literature review. Experts in the field of operations research are [1, $2,3]$. As experts, they recognized advantages in these methods; as example, the Simplex method implies a linear-programming algorithm that can solve problems having more than two decision variables and generating a series of solutions in tabular form much faster than other algorithms. The efficiency of these methods is also equally important for computer programming as the need of having lower processing power when they are applied. Additionally, an advantage of the transportation method is that the solution process involves only the main variables; artificial variables are not required. In the other hand, the simplex method presents some limitations to solve programming problems, it can only be used in certain linear programming problems and is difficult to adapt it to solve transportation problems; also, the simplex method involves time-consuming computations in the solution of problems that involves a large number of variables and constraints.

Figure 1 represents the methods used to solve this problem and explains the elements considered for the given solution.
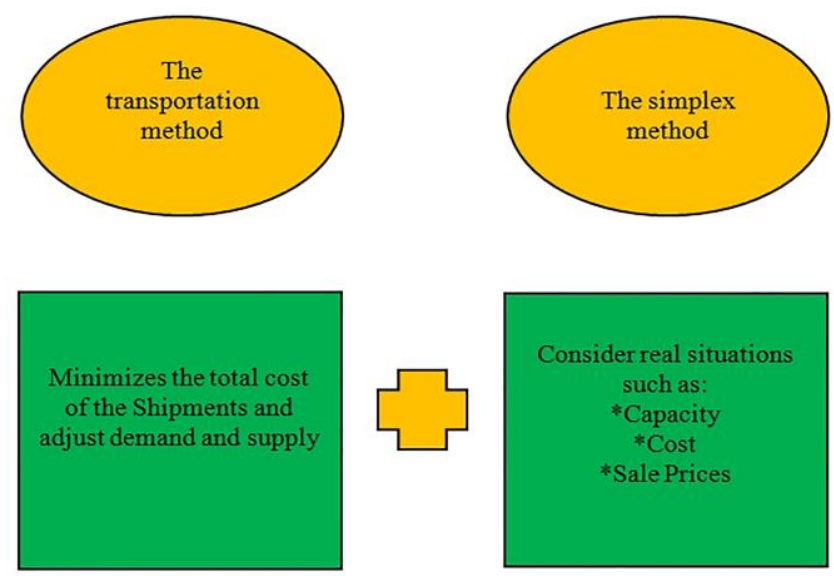

Fig. 1. The Transporting and Simplex Methods. 


\subsection{The Transportation Method}

This model seeks to define a supply network, the amount of product to be produced, the product destination, and the production centers by considering both constraints from resources and costs derived from materials storage and transport [4]. The main goal of this method is to determine the route for materials/product transport that implies the total minimum cost.

Data of this model must include:

1. Supply levels from every source and the amount of demand requested by every destination

2. Unit cost per product for every destination

Since there is only one kind of product, a same destination may receive its demand from one or several sources. The objective of this model is therefore to determine the amount of product that would be sent to every source in order to minimize the total cost of transportation [5]. The basic assumption of the model is that transport costs from one route are directly proportional to the number of units transported. The definition of transport unit depends on the kind of product that is handled.

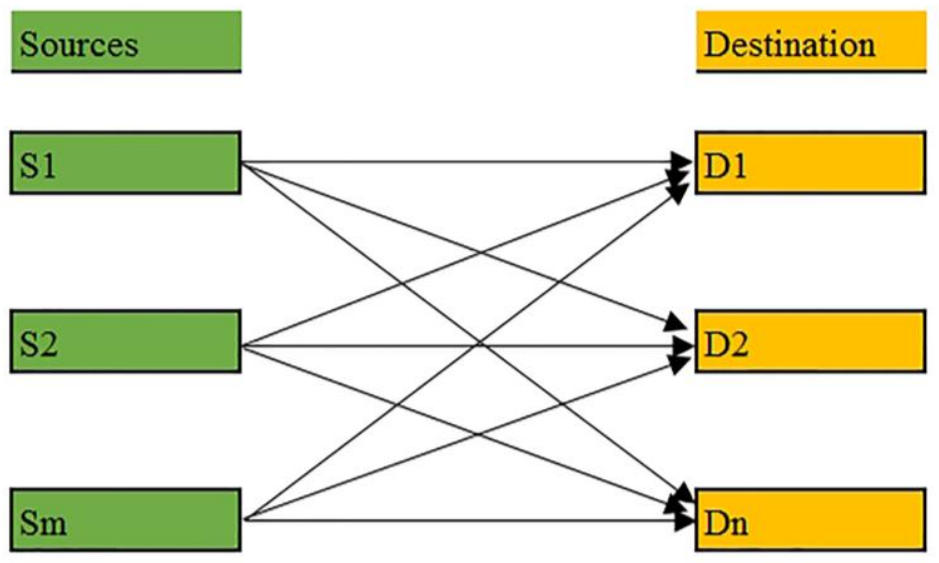

Fig. 2. Sources and destinations.

Every problem explained by this table can be considered as a transportation problem, even without considering its real physical context. For this reason, the transportation method has become one of the most important techniques in linear regression [6].

The following diagram represents the transportation model as a network with $\mathrm{m}$ sources and $n$ destinations. Sources and destinations are depicted by nodes, and the arch connecting a source with its destination stands for the route used to transport the product. The amount of supply in source $i$ appears as $a_{i}$, while demand from destination $\mathrm{j}$ is represented by $\mathrm{b}_{\mathrm{j}}$. Similarly, $\mathrm{C}_{\mathrm{ij}}$ refers to the unit transport cost between source $\mathrm{i}$ and destination $\mathrm{j}$. 
Therefore, if $\mathrm{X}_{\mathrm{ij}}$ stands for the amount of product transported from source $\mathrm{i}$ to destination $\mathrm{j}$, the linear programming (LP) model that represents the transportation model can be described as it follows:

$$
\text { Minimize } Z=S_{i}=1 m S_{j}=1 n C_{i j} X_{i j}
$$

subject to:

$$
\begin{array}{r}
S_{j}=1 n X_{i j} \leq a_{i}, \quad i=1,2, \ldots, m, \\
S_{i}=1 m X_{i j}>=b_{j}, \quad j=1,2, \ldots, n, \\
X_{i j}>=0 \text { for every } i \text { and } j .
\end{array}
$$

The first set of constraints states that the sum of deliveries from one source cannot be higher that this source's supply capacity. Likewise, in the second set, it is required that the sum of deliveries to a destination satisfies this destination's demand.

The model thus implies that the total supply $S i=1 \mathrm{~m}$ ai must at least equal the total demand $S j=1 n b j$. In this case, the resulting formulation is known as a balanced transportation model. Unlike in the regular transportation model, in this new one all constraints are equations.

That is:

$$
\begin{aligned}
& S X_{i j}=a_{i}, \quad i=1,2, \ldots, m, \\
& S X_{i j}=b_{j}, \quad j=1,2, \ldots, n .
\end{aligned}
$$

However, in real situations, supply is not necessarily equal to or higher than demand, but a transportation model can always be balanced. In addition to its functionality when modeling certain practical situations, balance is important to develop a solving method that fully exploits the special structure of the transportation model. The following two examples depict the idea of balance as well as its practical implications.

\subsection{The simplex method}

This method was first published by George Dantzig in 1947. It involves an iterative algorithm that, through iterations, sequentially approaches the optimal problem of linear programming if there is any [1, 2, 3]. Also, it was first computationally implemented in 1952 for a problem including 71 variables and 48 equations. The solution to such problem lasted 18 hours. Eventually, in 1956, IBM implemented the RSLP1 code with $4 \mathrm{~Kb}$ in RAM, which could handle LPs with up to 255 constraints [2]. The simplex method is based on the premise that the optimal solution to a LP problem lies on a vertex or on the boundary of the domain of feasible points (this only in special cases). Therefore, the sequential search of the algorithm is based on the progressive evaluation of such vertexes until the optimal one is reached. However, in order to apply the simplex method to a linear model, this model must be presented in a standard form, which will be described below. 


\subsection{Standard form of a linear programming model}

Consider the standard form of a LP model as it follows:

Min

$$
\begin{gathered}
c 1 x 1+c 2 x 2+\ldots+c n x n \\
a 11 x 1+a 12 x 2+\ldots+a 1 n x n=b 1 \\
a 21 x 1+a 22 x 2+\ldots+a 2 n x n=b 2 \\
a m 1 x 1+a m 2 x 2+\ldots+a m n x n=b m \\
x 1, \ldots, x n \geq 0 .
\end{gathered}
$$

Expressed in matrix form as:

$$
\begin{gathered}
\text { Min } \operatorname{cTx} A x=b, \\
x>=0 .
\end{gathered}
$$

It is assumed without loss of generality that the LP model is in its standard form.

\section{$3 \quad$ Methodology}

This section introduces the solution to the problem of fruit and vegetables transportation to the independent transporter in Ciudad Juarez. The different stages that lead to the solution are described in detail.

First, the Vogel approximation method is considered to solve the issue. Second, the three product destinations and their demand requested in the actual period are identified. These destinations focus on grocery sales in different parts of the city. Afterwards, sources are also defined, although, in this case, they are replaced by products offered.

When adjusting the supply and demand to solve the transportation problem, there is one essential element to consider: the fact that the amount of demand is provided by every destination and it does not change within the supply period. However, supply may be freely adjusted in order to meet the total demand of fruit and vegetables. Product units for both supply and demand are expressed in kilograms.

For the optimization of profits generated, data is presented by using a LP model as it is shown below:

$$
\begin{gathered}
\sum_{i=1}^{m} \sum_{j=1}^{n} u_{i j} x_{i j} \\
\operatorname{Max} z=5 x_{11}+5 x_{12}+5 x_{13}+6 x_{21}+6 x_{22}+6 x_{23}+8 x_{31}+8 x_{32}+8 x_{33}-1.8 x_{11}-1.8 x_{12} \\
-1.8 x_{13}-2.3 x_{21}-2.3 x_{22}-2.3 x_{23}-3.2 x_{31}-3.2 x_{32}-3.2 x_{33} \\
-2,100,
\end{gathered}
$$

subject to:

Fixed Cost: $x_{11}+x_{12}+x_{13}+x_{21}+x_{22}+x_{23}+x_{31}+x_{32}+x_{33}=\$ 2,100$,

Capacity in Kilograms: $x_{11}+x_{12}+x_{13}+x_{21}+x_{22}+x_{23}+x_{31}+x_{32}+x_{33} \leq 1,100$,

$$
\begin{gathered}
\text { Chili Pepper: } x_{11}+x_{12}+x_{13}=335, \\
\text { Watermelon: } x_{21}+x_{22}+x_{23}=425, \\
\text { Mango: } x_{31}+x_{32}+x_{33}=270,
\end{gathered}
$$




$$
\begin{gathered}
\text { Location 1: } x 11+x 21+x 31=460 \\
\text { Location } 2: x 12+x 22+x 32=220 \\
\text { Location 3: } x 13+x 23+x 33=350 \\
x_{i j} \geq 0
\end{gathered}
$$

where

$\mathrm{u}_{\mathrm{ij}}$ are pofits from transporting product units $\mathrm{i}$ to the destination $\mathrm{j}$, $\mathrm{x}_{\mathrm{ij}}$ is flow of product units $\mathrm{i}$ to the destination $\mathrm{j}$.

\section{$4 \quad$ Results}

The problem was introduced in the Excel Solver tool. Table 1 and Table 2 are data tables, and afterwards, the solution found is presented [7].

Table 1. Costs, sale prices, and fixed cost (in Mexican pesos).

\begin{tabular}{llll}
\hline & Cost & Sale Price & Fixed cost \\
\hline Chili pepper & $\$ 1.80$ & $\$ 5.00$ & $\$ 2,100$ \\
Watermelon & $\$ 2.30$ & $\$ 6.00$ & \\
Mango & $\$ 3.20$ & $\$ 8.00$ & \\
\hline
\end{tabular}

Table 2. Results from the matrix.

\begin{tabular}{lllll}
\hline & Location 1 & Location 2 & Location 3 & Supply \\
\hline Chili pepper & 182 & 57 & 96 & 335 \\
Watermelon & 157 & 110 & 158 & 425 \\
Mango & 121 & 53 & 96 & 270 \\
Demand & 460 & 220 & 350 & \\
\hline
\end{tabular}

The result obtained is:

$x 11=182, x 12=57, x 13=96, x 21=157, x 22=110, x 23=158, x 31=121, x 32=53, x 33=96$

Profitability found in this solution is $=\$ 1,840.50$ (Mexican pesos).

\section{Conclusions}

Using the simplex and the transportation methods together allows for the consideration of particular constraints to find the optimal solution to the problem that also satisfies transport requirements and generates the maximum profit. Constraints ensure 1) that the amount of product transported by every source equals the amount available, and that 2) the amount of product transported equals the amount required by every destination [7].

Therefore, based on the objectives initially proposed, it is concluded that considerable maximization of resources was actually achieved, since transport routes 
selected for the delivery of fruit and vegetables were the optimal ones. In the end, the independent transporter to whom support was provided felt satisfied with results obtained.

Nevertheless, the most effective solution to a transportation problem is not always found, since it is not an easy task to identify and differentiate the variables involved in every problem. Moreover, solutions to transportation problems may be complex. Therefore, it is crucial to correctly identify variables and expectations from every result obtained in order to correctly define the model [8-10].

Finally, advantages and disadvantages of both the simplex and transportation methods must be fully visualized to determine whether they may be applicable in a given situation and in which ways [11].

\section{References}

1. Taha, H.: Investigación de operaciones. Novena edición Pearson Educación, México (2012)

2. Taha, H.: Investigación de Operaciones. Pearson Educación, (2004)

3. Cely: Hybrid Meta-Heuristic Algorithms for Minimizing Entropy in Heat Transfer Problems that May Be Present in Electronic Circuits2. Print version ISSN 0123-2126 (2011)

4. García: Modelos para la planeación de transporte terrestre eficiente para el sector de hidrocarburos. Bogotá (2014)

5. García, A.: Investigación de operaciones. Available at: garciaescalona1.blogspot.com /2012/10/origen-de-la-investigacion-de.html (2012)

6. Garcia, J., Maheut, J.: Modelos y Métodos de Investigación de Operaciones. Procedimientos para Pensar. Available at personales.upv.es/jpgarcia/LinkedDocuments/ modeladomatematico.pdf (2012)

7. Ayil, E., Cauich, R., Moo, A., Urcid, A.: Investigación De OperacionesII. Available at: www.itescam.edu.mx/principal/sylabus/fpdb/recursos/r66942.PDF (2010).

8. Hillier, F., Lieberman, G.: Introducción a la Investigación de Operaciones. Available at: www.dropbox.com/s/xtlnulxtayqh2si/Introduccion $\% 20 \mathrm{a} \% 201 \mathrm{a} \% 20$ investigacion $\% 20 \mathrm{de} \%$ 20opera\%20-\%20Frederick\%20S.\%20Hillier.pdf (2010)

9. Nahmias, S.: En S. Nahmias, Análisis de la producción y las operaciones. México: McGraw-Hill, pp. 303-305 (2007)

10. Prawda: Métodos y Modelos de Investigación de Operaciones I: Modelos Determinísticos, Limusa, México (2004)

11. Cerda, I.: Optimization using the gradient and simplex methods. Talanta, Vol. 148, pp. 641-648 (2016) 